\title{
EVAPORATION EFFECT IN NONLINEAR PENETRATION OF HIGH ENERGY BEAM DRILLING
}

\author{
Je-Ee Ho \\ Department of Mechanical and Electrical Engineering, National I-Lan University, I-Lan County, Taiwan, R.O.C., \\ jeho@niu.edu.tw \\ Chen-Lung Yen \\ Department of Mechanical Engineering, National Taiwan University, Taipei, Taiwan, R.O.C.
}

Follow this and additional works at: https://jmstt.ntou.edu.tw/journal

Part of the Mechanical Engineering Commons

\section{Recommended Citation}

Ho, Je-Ee and Yen, Chen-Lung (2009) "EVAPORATION EFFECT IN NONLINEAR PENETRATION OF HIGH ENERGY BEAM DRILLING," Journal of Marine Science and Technology. Vol. 17: Iss. 2, Article 6.

DOI: $10.51400 / 2709-6998.1966$

Available at: https://jmstt.ntou.edu.tw/journal/vol17/iss2/6

This Research Article is brought to you for free and open access by Journal of Marine Science and Technology. It has been accepted for inclusion in Journal of Marine Science and Technology by an authorized editor of Journal of Marine Science and Technology. 


\title{
EVAPORATION EFFECT IN NONLINEAR PENETRATION OF HIGH ENERGY BEAM DRILLING
}

\author{
Je-Ee Ho* and Chen-Lung Yen**
}

Key words: enthalpy method.

\begin{abstract}
Due to the inappropriate assumption with the neglect of evaporation effect in previous research, a linear penetration behavior with a significant deviation from the experimental result was usually proposed in the lower energy density region. To remedy the defect, the evaporation mass determined from the difference between the melting rate and flow expulsion by pressure difference is reconsider in this study. With a 2-D quasic-steady model based on the enthalpy theory, the uniform penetration velocity estimated from the Stefan boundary condition provides a special advantage in calculating efficiency. Meantime, the divergent iteration has been effectively avoided by setting up a non-uniform distribution of grids in the numerical scheme; which also enables a successful prediction of nonlinear penetration behaviors, such as the material removal rate and penetration velocity versus incident energy density. Compared with the experimental data of Allmen [1], present model shows a good agreement for copper drilling in higher energy density region $\left(>7 \times 10^{10}\right.$ $\left.\mathrm{w} / \mathrm{m}^{2}\right)$, where the relative errors between the calculated and experimental data are no more than $10 \%$. Even the linear drilling result in lower energy density region has been further improved in this study.
\end{abstract}

\section{INTRODUCTION}

Nonlinear penetration behavior is an important phenomenon in high energy beam drilling, including the laser beam (L.B) and electron beam (E.B) methods. However, describing the rapid reaction between the evaporating atoms at the cavity base seems so complex that a full understanding of energy

Paper submitted 11/28/07; accepted 05/22/08. Author for correspondence: Je-EeHo (e-mail: jeho@niu.edu.tw).

*Department of Mechanical and Electrical Engineering, National I-Lan University, I-Lan County, Taiwan, R.O.C.

**Department of Mechanical Engineering, National Taiwan University, Taipei, Taiwan, R.O.C. transport inside the work piece is still lacking. Previous studies had discussed simpler models on penetrating velocity with energy density, such as the pure melting model [6] and single evaporating theory [5]. Both proposed mechanisms, a linear relation between the penetration velocity and energy density, seemed to only describe drilling behavior in lower energy densities. Allmen [1] predicted the penetrating efficiency by measuring the material removal rate, and those experimental results showed that a nonlinear relationship was observed during the energy intensity range of $5 \mathrm{Mw} / \mathrm{cm}^{2} \sim 20$ $\mathrm{Mw} / \mathrm{cm}^{2}$. Chiou and Wei [7] developed an axial symmetrical quasi-steady model to calculate the fluid flow of the liquid layer by considering the surface tension as the driving force; a surprising result showed that the calculated evaporation rate was only $1 / 1000$ of the melting mass. Ho and Young [3] proposed a 1-D model to describe the nonlinear behavior in a high energy beam. Their analytical solution was expressed as an exponential function in thermal property. This approach presented an excellent agreement in higher input energy density, but the predicted value was still overestimated during the lower input energy density.

In view of above unreasonable linear results, a more relevant relation between the energy absorption in evaporation and nonlinear behavior should be reconsidered. This is the objective of the present work.

\section{ANALYSIS}

To simplify the simulation model without losing penetration behavior, several reasonable assumptions should be made as follows:

1. Convective terms, due to a small Pelect number estimated near the cavity base, can be ignored without causing significant error.

2. Hydraulic pressure gradient whose order is much greater than that in surface tension force will be taken as the driving mechanism in the flow motion.

3. A $\mathrm{TEM}_{00}$ distribution of incident energy density [3] is assumed to irradiate on the cavity base with radius $0.1 \sigma$ bounded. 


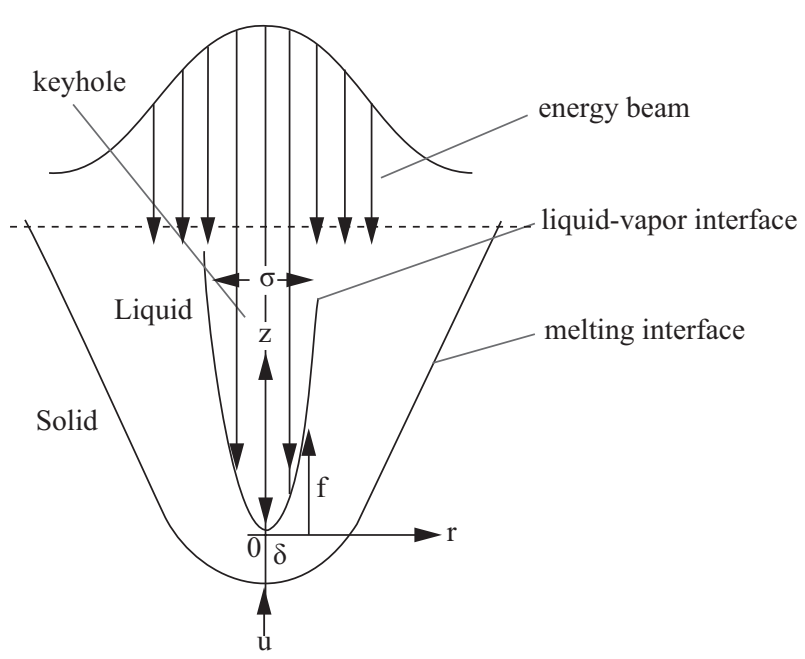

Fig. 1. Schematic sketch of high energy density beam.

\section{Governing Equations}

The formulation of the enthalpy equation with an axial symmetrical, quasi-steady state in both molten and solid zones can be expressed as:

$$
h=\left\{\begin{array}{cc}
\rho u \frac{\partial h}{\partial z}=\frac{1}{r} \frac{\partial}{\partial r}\left(k_{i} r \frac{\partial h}{\partial r}\right)+\frac{\partial}{\partial z}\left(k_{i} \frac{\partial h}{\partial z}\right) \\
c_{s}, T & T<T_{m}-\varepsilon \\
c_{s} T+\frac{h_{s 1}}{2 \varepsilon}\left(T-T_{m}+\mathcal{E}\right), & T_{m}-\varepsilon \leq T \leq T_{m}+\mathcal{E} \\
c_{1} T+h_{s 1}, & T_{m}+\mathcal{E}<T
\end{array}\right.
$$

\section{Boundary Conditions}

$$
\begin{array}{rllll}
-k_{l} \frac{\partial T}{\partial z}=h_{c}\left(T-T_{\infty}\right) \text { at } & z=3 \sigma & \frac{\partial T}{\partial r}=0 & \text { at } & r=0 \\
k_{s} \frac{\partial T}{\partial z}=h_{c}\left(T-T_{\infty}\right) \quad \text { at } & z=-3 \sigma & T=T_{\infty} \quad \text { at } & r=\infty
\end{array}
$$

Where $\sigma$ is the distribution radius that defines the region in which $75 \%$ of the incident energy is deposited and the enthalpy function $h$ smoothes the discontinuous enthalpy at the solid-liquid interface.

\section{1) Vapor-Liquid Interface}

An momentum conservation in (4), the balance between effective surface pressure and surface tension given by

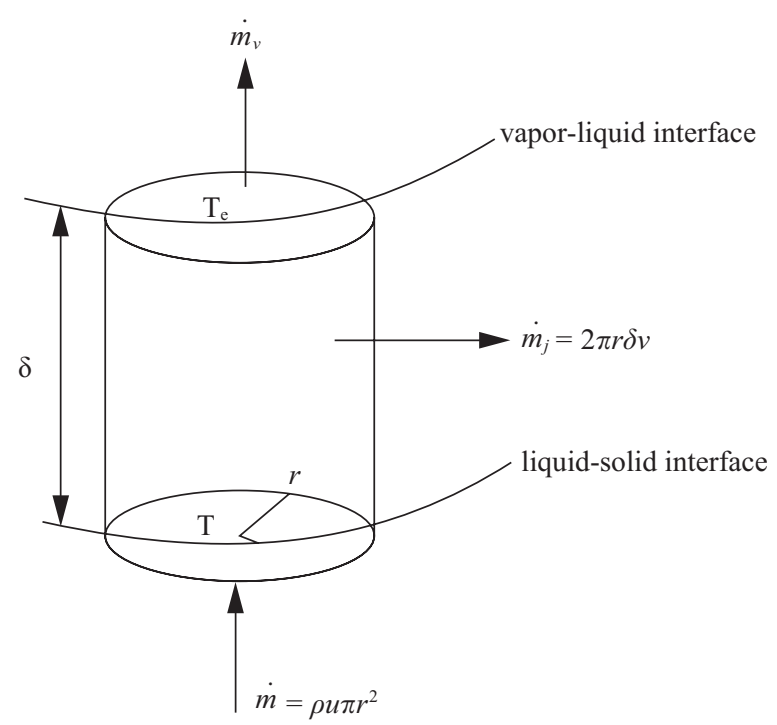

Fig. 2. Flow distribution.

Knight [4], is required to determine the surface temperature while the vapor-liquid interface is specified.

$$
\beta p_{b} \exp \left[\frac{h_{1 g}}{R_{g}}\left(\frac{1}{T_{b}}-\frac{1}{T}\right)\right]=\gamma\left(\frac{1}{R_{1}}+\frac{1}{R_{2}}\right)
$$

Where $\beta=0.55$ was also calculated by Knight, considering the thermodynamics non-equilibrium at the evaporating surface. The surface tension $\gamma$ at the bottom of the cavity is assumed to be a linear function of temperature along the free surface.

As to the energy conservation along the interface, the incident energy density dissipated by heat conduction and evaporation absorption yields

$$
q \exp \left(-\frac{r^{2}}{2 \sigma 2}\right)=-k\left(\frac{\partial T}{\partial r} \frac{d f}{d r}-\frac{\partial T}{\partial z}\right)+\rho u \eta_{v}
$$

\section{2) Liquid-Solid Interface}

Penetration velocity $u$ determined from the Stefan boundary conditiona at the liquid-solid interface can be expressed as

$$
\left.k_{l} \frac{\partial T}{\partial z}\right|_{z=-\delta}=\left.k_{s} \frac{\partial T}{\partial z}\right|_{z=-\delta}-\rho u h_{s l}
$$

\section{Evaporation Ratio}

As far as the mass flow conservation is concerned as sketched in Fig. 2, the melting rate $\dot{m}$ at the molten base will be shared by the evaporation rate $\dot{m}_{v}$ and the flow explusion rate $\dot{m}_{l}$, due to the pressure difference, at the bottom of the cavity. The $\dot{m}_{\ell}$ can be approximately estimated by Bernoulli's 
equation with the absence of friction drag set at $r=0$ and the pressure difference developed leads to

$$
\Delta p=A e^{-\frac{B}{T_{0}}}-A e^{-\frac{B}{T}}
$$

Evaporation ratio $\eta_{v}$ in (7) is defined as the evaporation rate for unit melting rate

$$
\eta_{v}=\frac{\dot{m}_{v}}{\dot{m}}=1-2\left(\frac{v}{u}\right)\left(\frac{\delta}{r}\right)
$$

Where $\dot{m}=\rho u \pi r^{2}, \dot{m}_{\ell}=2 \pi r \delta v \rho, \dot{m}_{v}=\dot{m}-\dot{m}_{\ell}$, and $v$ can be expressed as $\left[\frac{2 \Delta p}{\rho}\right]^{\frac{1}{2}}$

\section{Penetration Efficiency}

The penetration efficiency $\eta$ is defined as the extracted material volume per unit input power at $r=0$ and can be expressed as

$$
\eta=\frac{u}{q}
$$

where

$$
q=k_{1} \frac{\partial T}{\partial Z}+\rho u \eta_{v}
$$

\section{NUMERICAL PROCEDURE}

The discrete form of (1) and (2) with boundary conditions (3)-(6) can be obtained by using the central finite differences. A numerical scheme with $40 \times 30$ nodal points ensures the independence of the solution on the grid. Non- uniform nodal points are distributed in both the $\mathrm{r}$ - and $\mathrm{z}$ - directions, but have a greater concentration near the cavity base. To solve this problem, key steps developed are as follows.

(i) Specify the shape of the cavity first, and then calculate the temperature distribution along the vapor-liquid interface from (4).

(ii) Given the penetration velocity.

(iii) Iterate the enthalpy equations (1)-(2) with boundary conditions (3)-(4) using successive over-relaxation method with a relaxation factor of 1.25 until the solutions converge to a relative error limit of $0.5 \%$.

(iv) Estimate the penetration velocity from (6).

(v) If the relative error of the given penetration velocity and estimated value excesses 3\%, steps (iii) and (iv) should be kept running.

(vi) Compare the newest shape estimated from (5) and last shape of the cavity. If the relative error is more than
$5 \%$, update the latest geometry and repeat steps (i) (iv).

(vii) Determine the evaporation rate $\mathrm{m}_{\mathrm{v}}$, and penetration efficiency $\eta$ from (7) and (8), respectively.

(viii) Give the another input power q, repeat steps (i) (vii).

\section{EXPERIMENTAL PROCEDURES}

To verify the validation of the evaporation model in the nonlinear penetrating process, an E.B drilling equiment with the working capacity of accelerating voltage $60 \mathrm{kV}$ and working current $60 \mathrm{~mA}$ was used. During the experimental proceeding , the accelerating voltage was set at $60 \mathrm{kV}$; and 20 $\mathrm{mA}, 30 \mathrm{~mA}, 40 \mathrm{~mA}, 50 \mathrm{~mA}$ of working current was regluated by turns. In the meantime, the focal spot was restricted on the surface of the test sample, which provided an equivalent incident energy density of $4 \times 10^{10} \mathrm{w} / \mathrm{m}^{2} \sim 10 \times 10^{10} \mathrm{w} / \mathrm{m}^{2}$. The copper sheets with dimensions of $0.03 \mathrm{~m} \times 0.03 \mathrm{~m} \times 0.15 \mathrm{~m}$ were selected as the workpieces and a demagnetism polishing should be involved in the pre-processing, which prevented the influence of residual surface magnetic intensity on the acccelerating electrons. Four target spots were evenly distributed on the surface of the workpiece with a distance of $0.03 \mathrm{~m}$ respectively. A survey of E.B with a currant of $5 \mathrm{~mA}$ on these positions was necessary in advance.

To guarante a high working quality during the drilling process, a vacuum pump was operated continuously to keep a pressure of $10^{-6} \mathrm{~Pa}$ inside the working chamber. With the post processing on the drilling cavity, the samples were subsequently cut, polished and etched to reveal the patterns and the outlines of the fusion zone as shown in Figs. $3 \sim 5$ were captured by a 'DINO' digital microscope which was connected with a computer through a tranducer wire.

\section{RESULTS AND DISCUSSION}

The work piece was chosen to be copper and all figures provided were dimensional coordinates for comparison with experimental results and the data by Allmen.

The photographs in Figs. 3, 4, and 5 showing the drilling cavity were obtained for copper drilling under an incident energy density of $4 \times 10^{10} \mathrm{w} / \mathrm{m}^{2}, 6 \times 10^{10} \mathrm{w} / \mathrm{m}^{2}$, and $8 \times 10^{10} \mathrm{w} / \mathrm{m}^{2}$, respectively. A regular drilling hole without residual solidification left in Fig. 3 predicts that most of the molten metal might have evaporated into the keyhole to produce a continuous formation of the cavity and penetration mechanism is believed to be determined by evaporation model. In Fig. 4, the observed outline with a regular cavity shape and a smooth solidification with a flat level above the cavity base demonstrate that the molten metal in the cavity was nearly in static state, instead of a flowing motion. Another view from the cavity covered with a black liquid film leads to the prediction that the static liquid inside the cavity must have been overheated. According to above description, a strong evaporation, subjected to be a prior parameter, is predicted to be 


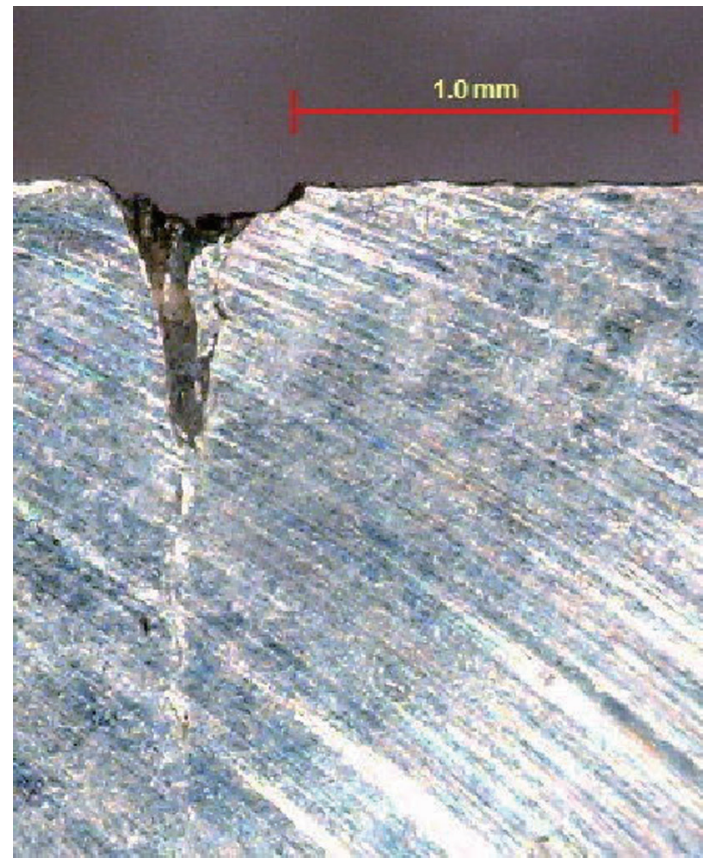

Fig. 3. Section view of copper cavity under the incident energy density $4 \times$ $10^{10} \mathrm{w} / \mathrm{m}^{2}$.

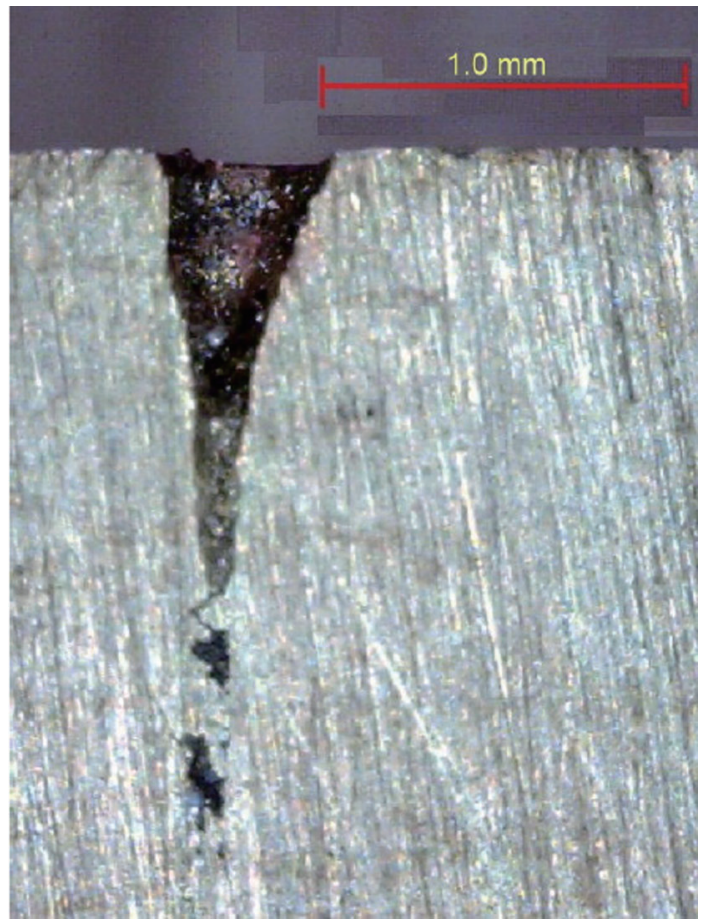

Fig. 4. Section view of copper cavity under the incident energy density $6 \times$ $10^{10} \mathrm{w} / \mathrm{m}^{2}$.

responsible for the formation of the cavity and should not be disregarded as the energy density was below $6 \times 10^{10} \mathrm{w} / \mathrm{m}^{2}$.

In contrast to the characteristics shown in Figs. 3 and 4, a jagged shape with a rough surface in Fig. 5 was caused by

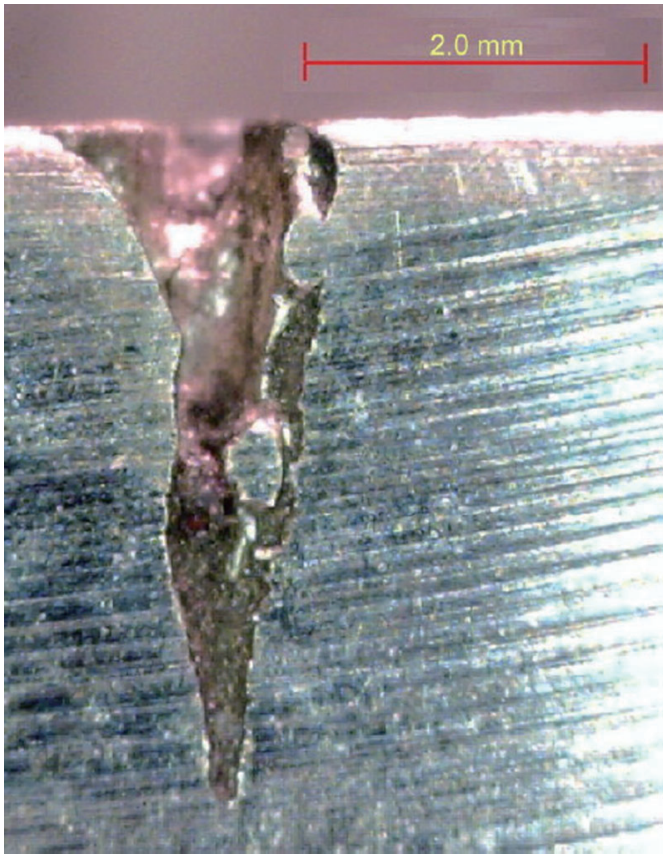

Fig. 5. Section view of the copper cavity under the incident energy density $8 \times 10^{10} \mathrm{w} / \mathrm{m}^{2}$.

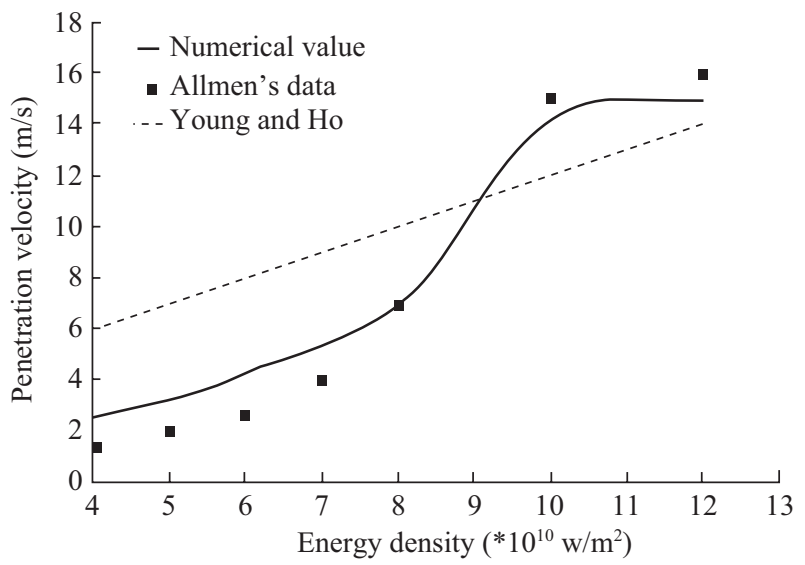

Fig. 6. Penetration velocity vs. energy density in copper drilling.

the expulsion of the molten flow under the action of the pressure difference; which not only had a deeper penetration, but also stirred an unsteady disturbance inside the cavity, where a non-uniform solidification of the molten part was left. In this model, the flow motion, due to the pressure difference, starts working and which will be taken as the driving mechanism to form the drilling cavity if the energy density is more than $8 \times 10^{10} \mathrm{w} / \mathrm{m}^{2}$.

Figure 6 illustrates the penetration velocity versus energy density. At the lower energy density $\left(<7 * 10^{10} \mathrm{w} / \mathrm{m}^{2}\right)$, the penetration velocity increases slightly from $2.3 \mathrm{~m} / \mathrm{s} \sim 4 \mathrm{~m} / \mathrm{s}$, and the slower penetration mechanism is primarily caused by the evaporation effect, which takes too much time to absorb the evaporation latent heat to penetrate into cavity as illustrated in 


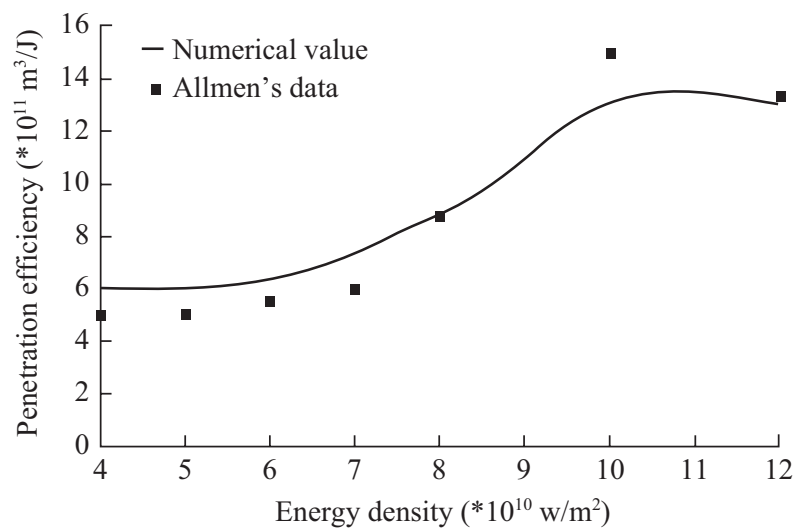

Fig. 7. Penetration efficiency vs. energy density in copper drilling.

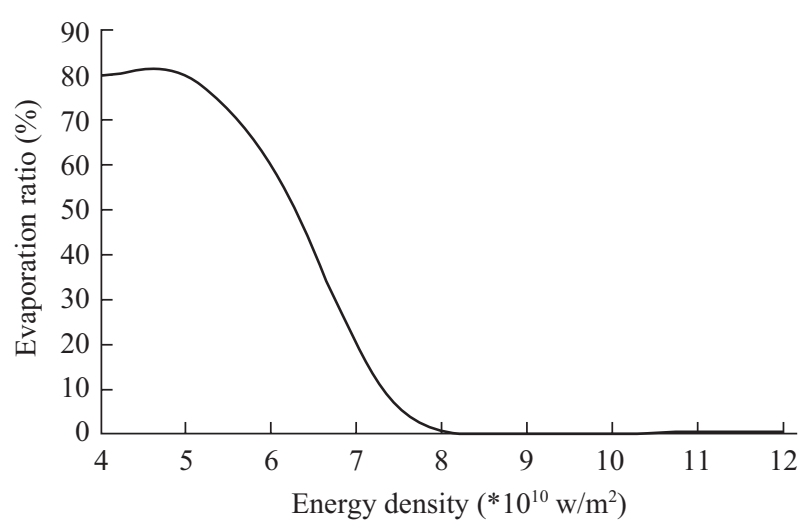

Fig. 8. Evaporating ratio vs. energy density in copper drilling.

Figs. 3 and 4. But for the higher energy density $\left(>8 * 10^{10}\right.$ $\left.\mathrm{w} / \mathrm{m}^{2}\right)$, the penetration velocity exhibits a nonlinear increase from $4 \mathrm{~m} / \mathrm{s} \sim 15 \mathrm{~m} / \mathrm{s}$ which corresponds to a molten flow driven quickly by pressure difference, instead of evaporation, to from a new cavity as shown in Fig. 5. Comparing with Allmen's experiments, the results are in close agreement with each other and the maximum relative error is less than $10 \%$ when the energy density excesses $7 * 10^{10} \mathrm{w} / \mathrm{m}^{2}$. Another comparison from a linear penetration model, $6 \mathrm{~m} / \mathrm{s} \sim 14 \mathrm{~m} / \mathrm{s}$, proposed by Young and Ho [3] shows that the drilling result will be apparently over estimated in the energy density below $7 * 10^{10} \mathrm{w} / \mathrm{m}^{2}$ if the evaporation effect is not involved.

Concerning the variation in penetration efficiency with different energy densities, Fig. 7 shows that a poor drilling efficiency of about $6^{*} 10^{-11} \mathrm{~m}^{3} / \mathrm{J}$ abruptly climbs up to $1.4 * 10^{-10}$ $\mathrm{m}^{3} / \mathrm{J}$ as the energy density varies from $4 * 10^{10} \mathrm{w} / \mathrm{m}^{2}$ to $10^{*} 10^{10}$ $\mathrm{w} / \mathrm{m}^{2}$ where the penetration velocity in Fig. 7 quickly increases from $2 \mathrm{~m} / \mathrm{s} \sim 15 \mathrm{~m} / \mathrm{s}$ with a faster growth than the energy density $\left(<10^{*} 10^{10} \mathrm{w} / \mathrm{m}^{2}\right)$ dose. The opposite result, i.e., a slow decrease of efficiency from $1.5^{*} 10^{-10} \mathrm{~m}^{3} / \mathrm{J}$ to $1.3^{*} 10^{-10}$ $\mathrm{m}^{3} / \mathrm{J}$, occurs when the energy density is more than $10^{*} 10^{10}$ $\mathrm{w} / \mathrm{m}^{2}$, while the stable value $15 \mathrm{~m} / \mathrm{s}$ in drilling velocity grows slowly than the increment of input energy density. Both tendencies, in Figs. 6 and 7, exhibit a similar distribution of the penetration velocity and efficiency with input power density applied. Moreover; the maximum drilling efficiency $1.5 * 10^{-10}$ $\mathrm{m}^{3} / \mathrm{J}$ occurring at $10 * 10^{10} \mathrm{w} / \mathrm{m}^{2}$ in Fig. 7 is produced when the drilling velocity reaches the stable value in Fig. 6. Comparing the numerical and experimental results shows that the agreement is good in most energy regions, especially in higher energy densities $\left(>9 * 10^{10} \mathrm{w} / \mathrm{m}^{2}\right)$ where the maximum relative error of $15 \%$ emerges at an input energy density of $10^{*} 10^{10}$ $\mathrm{w} / \mathrm{m}^{2}$.

According to the mass flow conservation, the evaporation mass ratio is defined as the evaporating rate per melting rate. From above definition, the distribution of evaporation ratio in Fig. 8 illustrates that about $60 \% \sim 80 \%$ of melting flow will evaporate into the drilling cavity when the energy density varies from $4 \times 10^{10} \mathrm{w} / \mathrm{m}^{2}$ to $6 \times 10^{10} \mathrm{w} / \mathrm{m}^{2}$. It tells that the domination of the evaporation effect in the formation of cavity can be predicted here. On the other hand, the continuous decrease of the ratio, from $60 \%$ towards $1 \%$, occurs within an energy density of $6 \times 10^{10} \mathrm{w} / \mathrm{m}^{2} \sim 8 \times 10^{10} \mathrm{w} / \mathrm{m}^{2}$, where the evaporation effect has fully lost its influence. In such case, almost all the molten flow with a minor evaporation will be carried to a radial direction by pressure difference, which is taken as the driving source in the formation of cavity and is also in concordance with above discussion.

\section{CONCLUSION}

The discussion above leads to the following important conclusions:

1. During the energy density below $7 \times 10^{10} \mathrm{w} / \mathrm{m}^{2}$ for copper drilling, a continuous formation of cavity is primarily caused by evaporation effect which should not be ignored.

2. Due to the extra duration required to absorb the latent heat in the evaporation process, it will slow down the penetration velocity and reduce the drilling efficiency. Conversely, a significant improvement of penetration behavior will be made as the flow motion, driven by pressure difference, is dominate in higher energy density region.

3 . The regular shape with smooth wall of cavity will be captured during the slower evaporation process. Otherwise, a coarse surface of keyhole pattern appears in faster penetration model.

4. The distribution of nonlinear penetration can be modified by the consideration of the evaporation effect in the lower energy density and an assumption of neglecting the convective terms without losing the drilling characteristic has been also identified in this study.

5. Detail analysis of various energy distributions in the workpiece will provide an extensive understanding on the nonlinear variation of drilling behavior in the future work.

\section{NOMENCLATURE}


$B \quad$ empirical constant for copper $40640[\mathrm{~K}]$

$C_{p i} \quad$ specific heat in both phases $[\mathrm{J} / \mathrm{kg} \mathrm{K}]$

$f \quad$ the location of liquid-vapor interface [m]

$h \quad$ enthalpy function $[\mathrm{J} / \mathrm{kg}]$

$h_{c} \quad$ convection coefficient $\left[\mathrm{W} / \mathrm{m}^{2} \mathrm{~K}\right]$

$h_{l g} \quad$ latent heat of evaporation $[\mathrm{J} / \mathrm{kg}]$

$h_{s l} \quad$ latent heat of melting $[\mathrm{J} / \mathrm{kg}]$

$k_{i} \quad$ thermal conductivity, $\mathrm{k}_{\mathrm{l}}$ or $\mathrm{k}_{\mathrm{s}}[\mathrm{W} / \mathrm{m} \mathrm{K}]$

$\dot{m} \quad$ melting rate $[\mathrm{kg} / \mathrm{s}]$

$\dot{m}_{l} \quad$ mass flow rate carried away by pressure difference

$[\mathrm{kg} / \mathrm{s}]$

$\dot{m}_{v} \quad$ evaporation rate $[\mathrm{kg} / \mathrm{s}]$

$p \quad$ vapor pressure [pa]

$P_{b} \quad$ saturated vapor pressure at boiling temperature

$Q_{0} \quad$ incident power [kw]

$q$ maximum incident energy flux, $\mathrm{Q} / 2 \pi \sigma^{2}\left[\mathrm{~W} / \mathrm{m}^{2}\right]$

$R_{g} \quad$ specific gas constant [J/kg K]

$T \quad$ temperature $[\mathrm{K}]$

$T_{m} \quad$ melting temperature $[\mathrm{K}]$

$T_{b} \quad$ boiling temperature $[\mathrm{K}]$

$T_{0} \quad$ bottom temperature of the cavity $[\mathrm{K}]$

$T_{\infty} \quad$ ambinet temperature [K]

$u \quad$ penetration velocity $[\mathrm{m} / \mathrm{s}]$

$\mathrm{z}, \mathrm{Z}$ dimensional and dimensionless vertical coordinate, $\mathrm{Z}=$ $\mathrm{z} / \sigma$, as illustrated in Fig. 1

$r, R$ dimensional and dimensionless radial coordinate, $\mathrm{R}=$ $\mathrm{r} / \sigma$, as illustrated in Fig. 1

$R_{1}, R_{2}$ principal curvatures of vapor-liquid interface [m]

$\alpha_{\mathrm{s}} \quad$ thermal diffusivity in solid phase $\left[\mathrm{m} / \mathrm{s}^{2}\right]$ $\alpha_{1} \quad$ thermal diffusivity in solid phase $\left[\mathrm{m} / \mathrm{s}^{2}\right]$

$\beta \quad 0.55$ was considered for thermodynamics nonequilibrium at evaporating surface.

$\delta \quad$ liquid thickness [m]

$\gamma \mathrm{m}$ surface tension at melting temperature $[\mathrm{Nt} / \mathrm{m}]$

$\rho \quad$ density of working material $\left[\mathrm{kg} / \mathrm{m}^{3}\right]$

$\sigma \quad$ distribution radius, reference length $[\mathrm{m}]$

$\eta \quad$ penetration efficiency $\left[\mathrm{m}^{3} / J\right]$

$\eta_{v} \quad$ evaporation ratio $[\%]$

$\frac{d \gamma}{d T} \quad$ surface tension gradient $[\mathrm{Nt} / \mathrm{m} \mathrm{K}]$

\section{REFERENCES}

1. Allmen, M. V., "Laser drilling velocity in metals," Journal of Applied Physics, Vol. 47, pp. 5460-5463 (1976).

2. Ho, J. E. and Ching, Y. H., "Computing the absorption of a drilling or welding hole for laser by using monte carlo method," Journal of the Chinese Society of Mechanical Engineers, Vol. 27, No. 1, pp. 61-67 (2006).

3. Ho, J. E. and Young, H. T., "The analysis on penetrating efficiency in high-energy beam drilling," Key Engineering Material, Vol. 364, pp. 308314 (2008).

4. Knight, C. J., "Transient vaporization from a surface into vacuum," AIAA Journal, Vol. 20, pp. 950-954 (1982).

5. Ol'Shanskii, N. A., "Movement of molten metal during electron beam welding," Svarochnoe Proizvodstvo, Vol. 21, pp. 12-14 (1974).

6. Ready, J. F., "Effects due to absorption of laser radiation," Journal of Applied Physics, Vol. 36, pp. 462-468 (1965).

7. Wei, P. S. and Chiou, L. R., "Molten metal flow around the base of a cavity during a high-energy beam penetrating process," Journal of Heat Transfer, Vol. 110, pp. 918-923 (1988). 